\title{
What is the role of motivation in procedural and conceptual physics learning? An examination of self-efficacy and achievement goals
}

\author{
Kelly Boden ${ }^{1}$, Eric Kuo ${ }^{1}$, Timothy J. Nokes-Malach ${ }^{1}$, Tanner LeBaron Wallace ${ }^{1}$, Muhsin Menekse ${ }^{2}$ \\ ${ }^{1}$ Learning Research and Development Center, University of Pittsburgh, Pittsburgh PA 15260 \\ ${ }^{2}$ Purdue University, 610 Purdue Mall, West Lafayette, IN 47907
}

\begin{abstract}
Studies of procedural and conceptual learning typically focus on the cognitive processes involved; less attention is paid to student motivation. Motivation research has established a connection to general academic achievement, but less is known about how motivation relates to different types of learning. We aim to integrate this prior work on cognition and motivation, testing how students' motivation is related to different types of learning outcomes. Specifically, we measured $6^{\text {th }}$ grade science students' self-efficacy and achievement goals via self-report as well as performance on both procedural and conceptual assessment items during a force and motion unit. Results revealed students' self-efficacy was significantly related to later conceptual, but not procedural, knowledge. In addition, students' achievement goals, specifically mastery-approach goals, were positively related to their self-efficacy beliefs.
\end{abstract}

\section{INTRODUCTION}

Physics students must learn procedures and concepts well enough to apply them to new problems $[1,2]$. Studies of procedural and conceptual learning typically focus on the cognitive processes involved in learning and less on student motivatio. In contrast, motivation research has largely focused on the relations between motivational factors and broad academic behaviors and general performance, without differentiating between different types of learning outcomes. The relations between motivation and different types of learning outcomes have been largely unexplored. Our current work aims to bridge this gap by identifying what motivational factors predict procedural and conceptual learning.

In this study, we considered two motivational factors when examining this issue: students' self-efficacy and achievement goals. To accomplish this, two methodological features were crucial. First, in addition to motivational measures, both procedural and conceptual learning must be assessed. Coarse-grained learning outcomes, such as course grade, cannot distinguish between these different learning outcomes. Second, there must be pre-test assessments of procedural and conceptual learning, in order to determine the relation between prior knowledge and motivation. While some studies in physics education have included these methodological features $[3,4]$ they are not common in the motivational literature in psychology.

We are also interested in better understanding what motivational factors are related to self-efficacy. Understanding relations to self-efficacy are important as self-efficacy has consistently been shown to predict science achievement, persistence in science majors, and science career choices [3]. Of particular interest are relations between achievement goals, self-efficacy, and prior knowledge. While prior work has established that achievement goals and self-efficacy are related [5], relations and potential changes in relations between these factors over the course of instruction is less known.

\section{BACKGROUND}

Self-efficacy (SE) is the belief in one's ability to succeed in specific situations or accomplish a task and has been related to increased effort, persistence, self-regulation, and academic achievement [6,7]. Positive reports of selfefficacy have been shown to predict problem-solving success and mediate the relations between prior experience and problem solving [7]. Further, self-efficacy has been related to physics course achievement $[3,4,8,9]$ and conceptual learning $[3,6]$.

While self-efficacy represents belief in ones' ability to perform a task, achievement goals are the reasons why one undertakes a competence-related task [10]. Three different achievement goals will be examined. A mastery-approach (MAP) goal emphasizes self-improvement, acquiring new skills and knowledge, and success is dependent on one's effort [11]. It has been related with positive perceptions of self-efficacy [5], deep processing [12], persistence on difficult tasks [13], and increased levels of interest [14]. A performance-approach (PAP) goal emphasizes displaying one's ability to others, outperforming others, and success

TABLE I. Motivational factors with the number of survey items and example items.

\begin{tabular}{|c|c|}
\hline $\begin{array}{l}\text { Self-efficacy } \\
(5 \text { items) }\end{array}$ & $\begin{array}{l}\text { If I study, I will do well or } \\
\text { a science test. }\end{array}$ \\
\hline $\begin{array}{l}\text { Mastery-approach } \\
(2 \text { items) }\end{array}$ & $\begin{array}{l}\text { My goal is to learn as } \\
\text { much as possible. }\end{array}$ \\
\hline $\begin{array}{l}\text { Performance- } \\
\text { approach } \\
(2 \text { items })\end{array}$ & $\begin{array}{l}\text { My goal is to perform } \\
\text { better than the other } \\
\text { students. }\end{array}$ \\
\hline $\begin{array}{l}\text { Performance- } \\
\text { avoidance } \\
(2 \text { items })\end{array}$ & $\begin{array}{l}\text { My goal is to avoid } \\
\text { performing poorly } \\
\text { compared to others. }\end{array}$ \\
\hline
\end{tabular}

is dependent on one's ability [13]. It has been related with both positive and negative outcomes including higher academic achievement as measured by grades [14], as well 
as shallow learning strategies $[5,15]$ and decreased interest [13]. A performance-avoidance (PAV) goal emphasizes not performing worse than others and has been related with negative learning strategies and outcomes including selfhandicapping strategies (procrastination, deliberately not trying, etc.) [12], decreased persistence on difficult tasks [14], and decreased academic achievement [5,15].

Although there is some preliminary work that has shown positive relations between mastery-approach goals and conceptual learning [16], no other work we know of has examined achievement goals and self-efficacy in relation to procedural and conceptual learning.

Procedural learning requires the execution of prior procedures to similar problems. For example (see table II), physics students learn to use the formula $v=d / t$ to calculate speed on new problems. In contrast, conceptual learning of problem content is the application of prior concepts and principles to new problems. For example, (see table II), physics students who learn that a net force produces acceleration can use this concept to predict the qualitative motion in new situations.

\section{RESEARCH HYPOTHESES}

With regards to the first research question - "what motivational factors predict procedural and conceptual learning?" - we had four hypotheses: (1) Students with higher self-efficacy in science class would show increased learning, both procedural and conceptual, due to prior work showing self-efficacy as related to various outcomes beneficial for learning in general (e.g., effort, persistence, etc.) $[6,7]$; (2) Students higher in mastery-approach goals would show higher levels of conceptual learning, due to

TABLE II. Example assessment items measuring procedural and conceptual learning.

\begin{tabular}{|l|l|l|l|}
\hline \multirow{2}{*}{$\begin{array}{l}\text { Example } \\
\text { Procedural } \\
\text { Item }\end{array}$} & Car & Time(s) & $\begin{array}{l}\text { Distance } \\
(\mathrm{m})\end{array}$ \\
\cline { 2 - 4 } & Joyride & 30 & 180 \\
\hline Flash & 35 & 260 \\
\hline Winner & 95 & 320 \\
\hline & $\begin{array}{l}\text { Three people were testing the speed of small model } \\
\text { cares. They recorded the data in the table. Which model } \\
\text { car went the fastest? }\end{array}$ \\
$\begin{array}{l}\text { Example } \\
\text { Conceptual } \\
\text { Item }\end{array}$ \\
\end{tabular}

prior work showing mastery-approach goals as related to outcomes that seem beneficial for conceptual, but not necessarily procedural learning (e.g., deep processing, persistence on difficult tasks, etc.) [12,13]; (3) Students higher in performance-approach goals would show higher levels of procedural, but not conceptual, learning as they've been related to academic achievement but also shallowlevel learning strategies $[5,15]$ that seem beneficial only to procedural learning; (4) Students higher in performanceavoidance goals would show lower levels of both procedural and conceptual learning as they've been shown to have overall negative effects on learning and performance $[12,14]$.

With regards to the second research question - "what motivational factors are related to self-efficacy?" - we had one hypothesis: mastery-approach goals, and none of the other achievement goals, would be significantly related to self-efficacy, as higher self-efficacy may result in the adoption of more difficult achievement goals, and vice versa.

\section{METHODOLOGY}

Seventy-six 6th-grade science students who were enrolled in one of two charter schools and completed all measures formed the final sample of this study. Although the schools each had a different teacher, they taught the same curriculum using the same core materials. This study focused on the force and motion unit, which utilized Smithsonian's Science \& Technology Concepts curriculum. The main approach of this curriculum is the use of hands-on activities designed to help students learn physical ideas through experiments, though readings and practice problems are also included. These materials primarily focused on teaching procedures for applying speed and motion ideas.

This study utilized two key measures. First, a motivation survey was used to measure students' self-efficacy and achievement goals in their science class (sample items shown in Table 1). Each item asked students to evaluate a statement on a 6-point Likert scale, from strongly disagree to strongly agree. Second, a set of questions on force and motion were used as a physics content test. This test consisted of both procedural and conceptual questions. The 8 procedural questions required students to know the definitions and equations for speed $(s=d / t)$ and kinetic energy $\left(\mathrm{KE}=1 / 2 \mathrm{mv}^{2}\right)$. Students had to perform calculations on word problems, read distance vs. time graphs, and explain proportional dependencies. The 8 conceptual questions were primarily qualitative questions on force and motion, either adapted directly from or styled like Force Concept Inventory (FCI) questions. One of the conceptual questions tested an experimental concept, control of variables.

The pre-motivation survey and procedural/conceptual pre-test were given approximately two days apart during the force and motion unit, before the focal lessons. These focal lessons included instruction on the speed equation, calculating speed from physical measurements of distance 
and time of rolling marbles, and investigating motion under a constant force through a fan cart. An identical procedural/conceptual post-test was given immediately after the focal lessons, approximately two weeks after the pre-test, and a post-motivation survey was given one week after that.

\section{RESULTS}

\section{A. What motivational factors predict procedural and conceptual learning?}

Overall, there was a significant gain from pre-test to post-test for procedural questions (Pre: $M=.31, S D=.19$; Post: $M=.45, S D=.24), t(75)=6.67, p<.001$, and for conceptual questions (Pre: $M=.33, S D=.20$; Post: $M=.41, S D=.24), t(75)=2.94, p=.004$.

Our primary question was whether students' incoming motivation would predict post-procedure or post-concept scores when controlling for prior knowledge. Table III shows the correlations of pre-motivation factors with procedural and conceptual pre- and post-scores. The only significant correlations between pre-motivation and postlearning scores were with self-efficacy, which was positively correlated with both post-concept and postprocedure score.

One possibility is that students' pre-self-efficacy simply reflected their pre-concept and pre-procedure performance. That is, their self-efficacy reflected their demonstrated problem solving competence. This possibility is illustrated through the significant correlation between pre-self-efficacy and pre-procedure score. To see if self-efficacy had an effect beyond prior knowledge, we used multiple regression to test relations between post-performance and pre-selfefficacy while controlling for students' pre-performance scores. The following regression results report standardized $\beta$ coefficients.

Table III. Bivariate correlations between pre-motivational factors and pre/posttest procedural and conceptual measures $(* \mathrm{p}<.05)$.

\begin{tabular}{lccccccc} 
Measure & $\mathbf{1}$ & $\mathbf{2}$ & $\mathbf{3}$ & $\mathbf{4}$ & $\mathbf{5}$ & $\mathbf{6}$ & $\mathbf{7}$ \\
\hline 1.Pre-SE & & & & & & & \\
2.Pre-MAP & .22 & & & & & & \\
3.Pre-PAP & .22 & $.24 *$ & & & & & \\
4.Pre-PAV & $.23^{*}$ & $.26^{*}$ & $.28^{*}$ & & & & \\
5.Pre-conceptual & .11 & -.08 & -.11 & -.10 & & & \\
6.Post-conceptual & $.28^{*}$ & -.07 & .01 & .07 & $.49 *$ & & \\
7.Pre-procedure & $.29 *$ & $-.23 *$ & .06 & -.06 & $.55^{*}$ & $.45^{*}$ & \\
8.Post-procedure & $.31 *$ & -.16 & .11 & .01 & $.51^{*}$ & $.42^{*}$ & $.66^{*}$ \\
\hline
\end{tabular}

First, we used this multiple regression approach to predict post-procedure score. Initially, pre-SE and pre-procedure score were used as predictors. This model accounted for $45 \%$ of the variance in post-procedural score, $F(2,73)=$
29.6, $p<.001$. After controlling for the significant effect of pre- procedure score, $\beta=.62, p<.001, s r^{2}=.35$, the effect of pre-SE was no longer significant, $p=.15$. A second model included the pre-concept score as a predictor. Even though prior conceptual knowledge should have a lesser impact on later procedural performance, this model ensured that we thoroughly tested the effect of prior knowledge. This addition significantly improved the fit of the model, $\Delta R^{2}=.03, F_{\text {change }}(1,72)=4.48, p=.04$. Preconcept score was a significant predictor of post-procedure score, $\beta=.22, p=.04, s r^{2}=.03$. The effect of pre-procedure score was still significant, $p<.001$, and the effect of pre-SE was still not significant, $p=.11$. In sum, when controlling for prior knowledge, pre-self-efficacy was not a significant predictor of post-procedure score.

Using the same multiple regression approach to predict post-concept score, we initially used pre-SE and preconcept score as predictors. This model accounted for $29 \%$ of the variance in post-concept score, $F(2,73)=15.1$, $p<.001$. Even after controlling for the significant effect of pre-concept score, $\beta=.46, p<.001, s r^{2}=.21$, pre-SE was a significant predictor of post-concept score, $\beta=.23, p=.02$, $s r^{2}=.05$. Again, a second model thoroughly controlled for prior knowledge, this time adding pre-procedural score as a predictor. Adding pre-procedure score did not significantly improve the model fit, $\Delta R^{2}=.02, F_{\text {change }}(1,72)=2.56$, $p=.11$.

Adding the three achievement goals (pre-MAP, prePAP, pre-PAV) into the regression models (either replacing pre- SE or in addition to it) neither produced any significant increases to overall model fit nor showed any significant relation between prior achievement goals and postperformance, all $p>.10$, confirming the pattern of results from simple correlations in Table III.

\section{B. What motivational factors are related to self-efficacy?}

We investigated the relation between post-achievement goals and post-SE. Table IV shows the correlations between post-motivation and post-performance factors. Post-SE was correlated with post-MAP, although post-concept score, post-procedure score, and pre-SE also correlate with postSE.

To examine whether the relation between post-SE and post-MAP would hold when controlling for other factors, a multiple regression was performed, using post-SE as the dependent variable and 6 independent variables: the 3 postachievement goals, post-procedural score, post-conceptual score, and pre-SE. The model accounted for $43 \%$ of the variance, $F(6,75)=8.49, p<.001$. In this multiple regression, the relation between post-SE and post-MAP was significant, $\beta=.32, p=.002, s r^{2}=.08$. The only other factor that was significantly related to post-SE in the model was pre-SE, $\beta=.35, p=.003, s r^{2}=.08$. Overall, the 
association between post-MAP and post-SE was robust, even controlling for multiple related factors.

Table IV. Bivariate correlations between post-motivational factors, post-procedural and post-conceptual measures, and pre-SE $(* p<.05)$.

\begin{tabular}{lcccccc} 
Measure & $\mathbf{1}$ & $\mathbf{2}$ & $\mathbf{3}$ & $\mathbf{4}$ & $\mathbf{5}$ & $\mathbf{6}$ \\
\hline 1.Post-SE & & & & & & \\
2.Post-MAP & $.45^{*}$ & & & & & \\
3.Post-PAP & .15 & $.28^{*}$ & & & & \\
4.Post-PAV & .19 & $.27^{*}$ & $.66^{*}$ & & & \\
5.Post-procedure & $.30^{*}$ & .00 & -.04 & .06 & & \\
6.Post-conceptual & $.36^{*}$ & .07 & -.08 & .00 & $.42^{*}$ & \\
7.Pre-SE & $.52^{*}$ & $.34^{*}$ & $.35^{*}$ & .18 & $.31^{*}$ & $.28^{*}$ \\
\hline
\end{tabular}

\section{DISCUSSION}

Overall, the present work reveals there is a relationship between motivation and particular learning outcomes in 6th-grade science classrooms. Specifically, self-efficacy is a significant predictor of conceptual learning, but not procedural learning, and this relationship holds even when controlling for students' prior knowledge. This finding suggests that students' beliefs about their ability are not simply a proxy for their prior knowledge.

Why should self-efficacy relate to conceptual rather than procedural learning? One hypothesis is that conceptual problems are intrinsically more difficult than procedural ones. Belief in ones' ability may enable one to persist during difficult conceptual problem solving. Self-efficacy may not be as important for procedural tasks, which simply require students to recognize opportunities to apply previously learned methods. Another hypothesis is that selfefficacy can help students engage in learning not manifest in instruction. The instructional materials used in the courses emphasized the formulas and procedures. Learning the underlying concepts may have required students to look beyond the instructional materials and a belief in one's own ability may have supported such efforts. Our results may also be a consequence of our self-efficacy measures being more sensitive to changes in conceptual rather than procedural gains. The measure of self-efficacy used was a more global measure that takes into account a number of views about competency within the class. It is not clear how students view their classroom competency in relation to procedural or conceptual competency. Future work could assess self- efficacy in relation to procedural and conceptual tasks separately to examine if there are differential effects.

Results also revealed post mastery-approach goals as significantly related to post self-efficacy. These two motivational factors were not significantly related in the pre-motivational survey, which was prior to instruction. This suggests that something over the course of instruction results in these two motivational factors being significantly related. Prior theoretical work has argued that self-efficacy may act as an antecedent to achievement goals and therefore produce achievement outcomes through the adoption of specific goals [17]. Our results may reflect this relationship. Conversely, achievement goals may act as an antecedent to self-efficacy. Adopting a mastery-approach goal may result in certain behaviors (i.e. deeper processing, persistence, etc.) that lead to better performance outcomes and increases in students' self-efficacy. More work is needed in order to reveal the paths and interconnections between these motivational constructs.

Because self-efficacy predicts learning outcomes above and beyond prior performance, future work could aim to better understand the relations between instruction, selfefficacy, and learning. This work could reveal how selfefficacy beliefs relate to study or problem solving strategies and provide valuable information on how best to intervene and promote self-efficacy within instruction.

\section{ACKNOWLEDGEMENTS}

This research was supported by NSF award DUE-1534829.
[1] J. Mestre, Phys. Today 44, 9 (1991).

[2] R. Leonard et al., Am. J. Phys. 64, (1996).

[3] A. Cavallo, W. Potter, and M. Rozman, School Sci. Math. 104, 6 (2004).

[4] L.E. Kost, S.J. Pollock, and N.D. Finkelstein, in Proceedings of the American Institute Physics Conference, Ann Arbor, 2009, edited by M. Sabella, C. Henderson, and Ch. Singh, p. 177.

[5] J. Meece, E. Anderman, and L. Anderman, Annu. Rev. Psych. 57, (2006)

[6] A. Bandura and D. Schunk, J. Personality Soc. Psych. 41 (1981).

[7] F. Pajares, Rev. Educ. Res. 66, 4 (1996).

[8] K. Shaw, in Proceedings of the American Institute Physics Conference, Sacremento, 2004, edited by J. Marx, S. Franklin, and K. Cummings, p. 137.
[9] J. Dowd, I. Araujo, and E. Mazur, Phys. Rev. ST Phys. Educ. Res. 11, 010107 (2015).

[10] A. Elliot, Educ. Psychologist 34, 3 (1999).

[11] C. Ames and J. Archer, J. Educ. Psych. 80, 3 (1988).

[12] A. Elliot, H. McGregor, and S. Gable, J. Educ. Psych. 91, 3 (1999).

[13] C. Hulleman, A. Durik, S. Schweigert, and J. Harackiewicz, J. Educ. Psych. 100, 2 (2008).

[14] E. Anderman and H. Patrick, The handbook of research on student engagement (Boston, MA, 2012), p. 173.

[15] C. Midgley and T. Urdan, Contemp. Educ. Psych. 26, (2001).

[16] D. Belenky and T.J. Nokes-Malach, Learn. Indiv. Diff. 25, (2013).

[17] A. Elliot and T. Thrash, Jour. Personality Soc. Psych. 82, 5 (2002). 